\title{
The technique of physical rehabilitation in clubfoot
}

\author{
DOI: https://doi.org/10.5114/pq.2019.83058
}

\author{
Natalia Nesterchuk', Igor Grygus', Krzysztof Prusik², Walery Zukow ${ }^{3}$ \\ ${ }^{1}$ Institute of Health, National University of Water and Environmental Engineering, Rivne, Ukraine \\ ${ }^{2}$ Gdansk University of Physical Education and Sport, Gdańsk, Poland \\ ${ }^{3}$ Nicolaus Copernicus University in Toruń, Toruń, Poland
}

\section{Abstract}

Introduction. To develop the technique for physical rehabilitation of children with congenital clubfoot. To prove the positive influence of physical rehabilitation available to correct disorders in children with congenital clubfoot.

Methods. The pedagogical experiment involved 68 preschool children aged 4-5 years with congenital clubfoot, who were divided into the control $1(n=34)$ and main $(n=34)$ groups. At the beginning of the study, the children were treated and were classified in the 'D' register by the children's orthopaedist. Peers without developmental disorders $(n=34)$ constituted the control group 2.

Results. The physical rehabilitation technique based on the methods of functional status diagnosis, purpose, content, and physical rehabilitation program included 3 stages of implementation. The basic technique components of physical rehabilitation experimentally verified its effect on correcting the basic disease and functional status of children with congenital clubfoot. The emphasis was placed on the active involvement of parents, establishing close and trusting relationships with them. Parents are taught to correctly apply physical rehabilitation. They have mastered the skills required for the organization of physical rehabilitation at home.

Conclusions. The technique was based on physical rehabilitation purpose, objectives, and adequate principles. It also discloses the specific organization and methodology of physical rehabilitation in congenital clubfoot. The guiding direction is to achieve physical rehabilitation of motor activity and functional status of children with congenital clubfoot to the level of their peers without disabilities.

Key words: technique, physical rehabilitation, children, congenital clubfoot

\section{Introduction}

Congenital clubfoot is characterized by a complex deformation of the foot. According to the statistics of medical institutions, congenital clubfoot is the most common disorder among congenital diseases of the musculoskeletal system, with the prevalence of $35.8 \%$. Bilateral clubfoot prevails over one-sided disorder. In $10 \%$ of patients, the deformity is combined with other congenital malformations (throat dislocation, syndactyly, cleft lip and cleft palate, etc.), indicating a violation of the normal development of the embryo in the $1^{\text {st }}$ half of pregnancy under the influence of various teratogenic factors [1, 2].

Pathological changes in congenital clubfoot occur not only in the foot but extend to the entire skeleton of the lower limb and even to the pelvis and spine. To a significant degree, clubfoot affects the bone. It changes its shape and position in the fork of the ankle joint, so movements do not occur in the anterior-posterior but in the lateral direction. The abnormally developed ankle (the outer part often reaches large sizes) prevents foot correction during treatment. Particularly severe changes are found in soft tissues (ligaments, tendons, and muscles).

With the growth of the baby, especially with the onset of walking, under the influence of the load, the clubfoot increases. The support lies on the outer edge of the foot, where, over time, a skin softening occurs and so-called natoptiches are formed. In one-sided clubfoot, there is a marked shortening of the foot and pronounced atrophy of the leg muscles, which result in their conical shape. The muscle atrophy increases with age owing to a considerable restriction of movements in the ankle joint. Functional violations progress as the deformation increases [3, 4].

The problem of physical rehabilitation in the presence of congenital clubfoot at the present stage of physical therapy development continues to be extremely controversial and, in most cases, is reduced to generally accepted methods, such as orthopaedic footwear, without the complex application of all means of physical therapy.

Even if significant progress is made in the treatment of this pathology, a significant level of unsatisfactory results and relapse is observed, which requires physical rehabilitation.

In spite of the numerous studies on the treatment and surgical intervention for clubfoot, implementing physical rehabilitation in children of all age groups remains relevant. In scientific literature, the scope of additional research methods needed to determine the degree of congenital clubfoot severity needs to be clarified $[5,6]$. Scientific research has proved the need for an introductory period of physical rehabilitation to focus on correcting the pathological position of the foot, the formation of motor skills. The main period of physical rehabilitation involves the use of tools and methods for improving the position of the ankle joint and strengthening the muscles of the lower extremities. The final physical rehabilitation period is devoted to improving skills and motor activities, as well as promoting prevention of relapse [7].

Correspondence address: Walery Zukow, Faculty of Earth Sciences, Nicolaus Copernicus University, ul. Lwowska 1, 87-100 Toruń, Poland, e-mail: zukow@umk.pl

Received: 30.11 .2018

Accepted: 08.01.2019

Citation: Nesterchuk N, Grygus I, Prusik K, Zukow W. The technique of physical rehabilitation in clubfoot. Physiother Quart. 2019;27(1):25-34; doi: https://doi.org/10.5114/pq.2019.83058. 
In the process of implementing physical rehabilitation, it was suggested not only to influence the main pathology, but also to exert a positive effect on the development of respiratory and cardiovascular systems in children. A previous experiment confirmed the efficiency of the developed concept of physical rehabilitation with regard to the functional status of the cardiovascular and respiratory systems in children [8].

According to scientists, after major surgical interventions, the formation of a scar and adhesion process of the tendons with restrictions of the foot function are noted, even in the absence of residual deformation [9, 10]. Shikhaleva [11] believes that outpatient rehabilitation plays a key role in maintaining the result of surgical treatment for congenital clubfoot in children. As a constituent of a complex of medical and rehabilitation measures, physiotherapy procedures should be applied. Kadzhaya [12] proved the expediency of a differentiated choice of means of treatment depending on the degree of motor disorders in congenital clubfoot, and the need for timely evaluation of treatment effectiveness owing to changes in the neuromuscular system in children with congenital clubfoot, characterized by a decrease in muscle functional capacity. Vlasov [13] observed that one of the main causes of failure in the treatment of congenital clubfoot was an inadequate assessment of the pathological displacement of the small thoracic bone in the distal tibia and spatial disturbances of the position and size of the tibia and fork of the ankle joint. Bondarenko [14], in a study of domestic and foreign surgical experience, indicates that the existing methods of surgical treatment do not fully restore the foot anatomy or function in the treatment of severe degrees of congenital clubfoot in children. Krestyashin [15] points out the necessity of a constant follow-up in children with congenital clubfoot, with the control of the ankle joint function up to the age of 15 years.

As for the rehabilitation of preschool age children with congenital clubfoot, some researchers [16-18] substantiated the method of medical rehabilitation. It specifies the effective means and techniques of integrated treatment and rehabilitation [19-21]; more than 300 safe and simple clinical tests for assessing the status of bones, joints, and muscles have been proposed [22].

Despite the advances in modern medicine and significant experience in the treatment of clubfoot, the recommendations for the individualization of physical rehabilitation in children with congenital clubfoot remain undeveloped. The issue of preventing relapses and the optimal technique for their elimination should be highlighted, which determines the need to develop and implement individualized content of physical rehabilitation of children with congenital clubfoot in preschool period. The following problems should be addressed: first of all, correction of the existing pathology and deformation; restoration and improvement of the body systems function; prevention of possible relapses.

Thus, the development of the technique of physical rehabilitation of children with congenital clubfoot is an urgent task. The technique should contribute to creating optimal conditions for the restoration of proper relationships between the elements of the foot and for early compensation of the lower limb function.

As a hypothesis, we foresee that the use of a physical rehabilitation technique improves the functional status of children with congenital clubfoot and normalizes foot function.

The aim of the study was to develop the technique for physical rehabilitation of children with congenital clubfoot, as well as to substantiate the positive effect of physical rehabilitation on correcting the existing disorders in children with congenital clubfoot.

\section{Subjects and methods}

\section{Participants}

The pedagogical experiment involved 102 children of preschool age, including 68 with congenital clubfoot, who took the course of physical rehabilitation at the centre of early pedagogical rehabilitation and social adaptation of children with special needs 'Pahinets' in Rivne in years 2016-2017, living with their families. All children were constantly followed up by an orthopaedic doctor in the city's complex children's hospital and Rivne Regional Children's Hospital. For physical rehabilitation, the participants with congenital clubfoot were randomly allocated (with a table of random numbers) to the control 1 ( $n=34)$ and main $(n=34)$ groups (age $4-5$ years); control group 2 included healthy peers $(n=34)$. Detailed distribution of subjects in the groups is presented in Table 1.

At the beginning of the study, the children were treated and were classified in the 'D' register by the children's orthopaedist. The study involved a sample of preschool age children with congenital clubfoot, ICD-10 code Q66. In accordance with the classification (ICD-10), the children were diagnosed at birth with a typical congenital clubfoot (idiopathic embryonic defect of lower limb development, characterized by a dysplasia and stable dislocation of all structures of the foot, especially its middle and posterior sections).

The study criteria for inclusion were as follows:

- diagnosis after birth: heavy bilateral clubfoot with severe movement constraints, III degree;

- treatment: applying plaster bandages with gradual correction of the feet position from 2-4 weeks of age;

- surgical intervention carried out in the period from 9 to 11 months; later, plaster bandages applied for 4-6 months to maintain the result of surgical intervention;

- restriction of movement in the ankle joint;

- presence of anterior foot department deformities;

- age $4-5$ years.

The following criteria were used for exclusion:

- diagnosis after birth: one-sided fistula and/or I or II degree of congenital clubfoot;

- acquired clubfoot;

- age over 5 years;

- absence of movement restriction in the ankle joint;

- parents' refusal to regularly conduct physical rehabilitation of children.

Considering the pathology of the children, the following anthropometric parameters were selected for further research: height, length of the foot, width of the foot (Table 2).

\section{Intervention}

The experimental research was based in the Rivne oblast sports centre 'Rivne Invasport organization' (rehabilitation groups of preschool children), the centre for early education rehabilitation and social adaptation of children with special needs 'Pahinets,' Rivne regional centre for medical and social services (provision of social services), and centre for rehabilitation of the disabled with musculoskeletal disorders at Rivne complex children's hospital and Rivne Regional Children's Hospital.

The researchers conducted physical rehabilitation classes, provided therapeutic treatment to the lower extremities of children with congenital clubfoot, consulted the parents on physical rehabilitation tasks. With a massage therapist, they arranged massage training for parents. With an orthopaedic surgeon, they produced auxiliary means for holding the disabled foot in hypercorrection. The researchers took active 
Table 1. Distribution of the children in the groups

\begin{tabular}{|c|c|c|c|c|c|c|c|}
\hline \multirow{2}{*}{ Age } & \multirow{2}{*}{ Sex } & \multicolumn{2}{|c|}{ Control group 1 } & \multicolumn{2}{c|}{ Main group } & \multicolumn{2}{c|}{ Control group 2 } \\
\cline { 2 - 8 } & & number & $\%$ & number & $\%$ & number & \% \\
\hline \multirow{3}{*}{4 years } & girls & 7 & 20.59 & 8 & 23.53 & 23.53 \\
\cline { 2 - 9 } & boys & 11 & 32.35 & 10 & 29.41 & 10 & 29.41 \\
\hline \multirow{2}{*}{5 years } & girls & 8 & 23.53 & 7 & 20.59 & 7 & 20.59 \\
\cline { 2 - 9 } & boys & 8 & 23.53 & 9 & 26.47 & 9 & 34 \\
\hline
\end{tabular}

Table 2. Anthropometric indicators of the subjects $(M \pm m)$

\begin{tabular}{|l|c|c|c|c|c|}
\hline \multirow{2}{*}{} & \multicolumn{2}{|c|}{ Age: 4 years } & \multicolumn{2}{c|}{ Age: 5 years } \\
\cline { 3 - 6 } & \multicolumn{2}{|c|}{$\begin{array}{c}\text { Children with } \\
\text { Indicators }\end{array}$} & $\begin{array}{c}\text { Peers without } \\
\text { developmental } \\
\text { disorders } \\
(n=36)\end{array}$ & $\begin{array}{c}\text { Children with } \\
\text { congenital clubfoot } \\
(n=32)\end{array}$ & $\begin{array}{c}\text { Peers without } \\
\text { developmental } \\
\text { disorders } \\
(n=16)\end{array}$ \\
\hline Height $(\mathrm{mm})$ & $1030 \pm 5.75$ & $1049 \pm 8.57$ & $1074 \pm 5.81$ & $1076 \pm 11.14$ \\
\hline \multirow{2}{*}{ Foot length $(\mathrm{mm})$} & left & $145 \pm 0.62$ & $174 \pm 1.16$ & $153 \pm 1.22$ & $186 \pm 1.70$ \\
\cline { 2 - 6 } & right & $145 \pm 0.66$ & $174 \pm 1.16$ & $153 \pm 1.41$ & $186 \pm 1.67$ \\
\hline \multirow{3}{*}{ Foot width $(\mathrm{mm})$} & left & $71.6 \pm 0.34$ & $61 \pm 0.55$ & $74.5 \pm 0.44$ & $64.2 \pm 0.57$ \\
\cline { 2 - 6 } & right & $71.7 \pm 0.32$ & $61 \pm 0.54$ & $74.6 \pm 0.48$ & $64.4 \pm 0.54$ \\
\hline
\end{tabular}

part in conducting seminars and discussions with parents; they formulated homework for children.

All children were inspected and remained under constant supervision of an orthopaedist.

\section{Data analysis}

The mathematical processing of digital data was carried out with the methods of variation statistics: the method of average values, the selective method of calculation of the arithmetic mean ( $M)$, sample dispersion (S2), mean square deviation $(m)$, errors in the arithmetic mean $(m)$, Student's criterion $(t)$, level of statistical significance $(p)$. Since the data obtained as a result of our research obeyed the normal distribution law, which was checked with $\mathrm{x}^{2}$ - the Pearson criterion, $t-$ the Student's criterion among the arithmetic means, we assumed the difference significance at the level of $p<$ 0.05 with a given number of degrees of freedom.

The statistical description of the samples was made by defining the arithmetic mean $(M)$ and its error $(m)$. The type of parameter distribution in the variation series was determined by the criterion of Shapiro-Wilk. The significance of the differences between the samples was estimated with nonparametric methods for dependent and independent samples (Wilcoxon $T$-criterion, Mann-Whitney $U$-criterion). The criterion for the reliability of the estimates was the level of significance with the indication of the probability of erroneous assessment $(p)$. The assessment of the mean difference was considered significant at $p<0.05$. The calculation software used was Excel XP and Statistica 6.0 (StatSoft, USA).

\section{Organization of the research}

In order to prove the effectiveness of the technique of physical rehabilitation, a number of diagnostic tests and control exercises were used.
The volume of movement in the ankle joint and foot was determined by measuring the angles (goniometer). The anthropometric methods included measurements of the foot width and length.

To determine the mobility of the ankle and anterolateral joints of the foot, as well as the volume of movements in these joints, measurements of the angles of the foot were performed in 3 positions from the inside: at right angles to the foot; in the position of maximum passive movement of the shin forward with the transfer of the body mass; in the position of maximum passive displacement of the tibia back under the influence of the body mass with straightened leg. In this case, the angles are formed: the position of the shin relative to the support in different positions. In the position of maximum passive movement of the shin forward, under the influence of the body mass, an acute angle is formed $\angle$ a. In the position of maximum passive displacement of the leg back under the influence of the body mass at the straightened leg, an obtuse angle is formed $\angle b$. With the help of the angles, in accordance with the position of the shin in relation to the support, in 3 positions, you can calculate the total motion of the shin relative to the support surface:

$$
\angle \text { in }=\left(90^{\circ}-\angle \mathrm{a}\right)+\left(\angle \mathrm{b}-90^{\circ}\right)
$$

The physical development of children with congenital clubfoot was investigated by physical exercises that corresponded to the biological age of the subjects, and assessed in accordance with an international evaluation of the main motor functions: 0 points (cannot perform) if the child was unable to perform a certain exercise; 1 point (tries to perform) if the child tried to perform it or needed a physical assistance from an adult; 2 points (partially performs) if the child performed the exercise on their own but with significant errors; 3 points (fully performs) if the child performed the exercise on their own without gross errors, adhering to all requirements for the execution of a certain action. 
Control exercises for walking were as follows: (1) walking with a high knee lift; (2) walking on socks; (3) walking on heels; (4) walking on the inside of the foot; (5) walking in small steps; (6) walking in broad steps; (7) deep squat walking; (8) crossstep walking; (9) walking backwards; (10) walking with an attached step left side with movement of hands; (11) walking step by step with the right hand side with the movements of the hands [23, 24].

Control exercises for running were as follows: (1) running on socks; (2) high knee racing; (3) running a wide step; (4) running with overcoming obstacles - running around objects; (5) running with overcoming obstacles - jump items; (6) running the distance of 100-150 $\mathrm{m}$ at an average speed 3-4 times, at a slow pace [23, 24].

Equilibrium was observed with the help of Bondarevsky test with open and closed eyes [23, 24].

Physical performance of children with congenital clubfoot was determined with the use of the Ruffier functional test $[23,24]$.

The technique of physical rehabilitation reflects the theoretical and methodological foundations, the purpose, the statement of tasks, the allocation of adequate principles, the specifics of the physical rehabilitation organization, the methodical principles of the use of physical rehabilitation facilities for congenital clubfoot. The focus of physical rehabilitation is to achieve the maximum possible development, motor activity, and functional status of children with congenital clubfoot to the level of their peers without disturbances of development (Figure 1).

The introductory phase focused on the correction of the pathological position of the feet, mastering the skills of correct implementation of the main movements, and the formation of motor skills.
During the main stage, we accentuated increasing mobility and improving the functional status of the ankle joint, strengthening the muscles of the lower extremities, the overall physical development of children, improving anthropometric indicators of the foot, development of physical capacity.

The final stage aimed at securing the skills acquired - performing physical exercises, improving motor skills, implementing the major movements, preventing relapse.

Optimal methods of organizing classes were considered in the individual and group context.

The forms of physical rehabilitation included: morning hygienic gymnastics, therapeutic exercises, independent exercises, medical walking, sports exercises and games, weekend hikes, health and sports holidays.

The process of physical rehabilitation was marked by a focus on the development of mobility and improvement of the functional status of the ankle joint, the correction of the pathological position of the feet, strengthening the muscles of the lower extremities, adjusting the main movements, ensuring the comprehensive overall physical development of children, preventing relapse, improving anthropometric parameters (ratio of the height to the length of the foot; ratio of the length of the foot to its width), stretching (the Achilles tendon, muscles, and the ligaments of the lower extremities).

As a result, the children were provided with the following means of physical rehabilitation: general development exercises, special exercises (for the development of mobility and improvement of the functional status of the ankle joint), exercises for strengthening the muscles of the lower extremities, adjusting the main movements, comprehensive general physical development, mobile games, physiotherapy procedures, therapeutic massage, stretching.

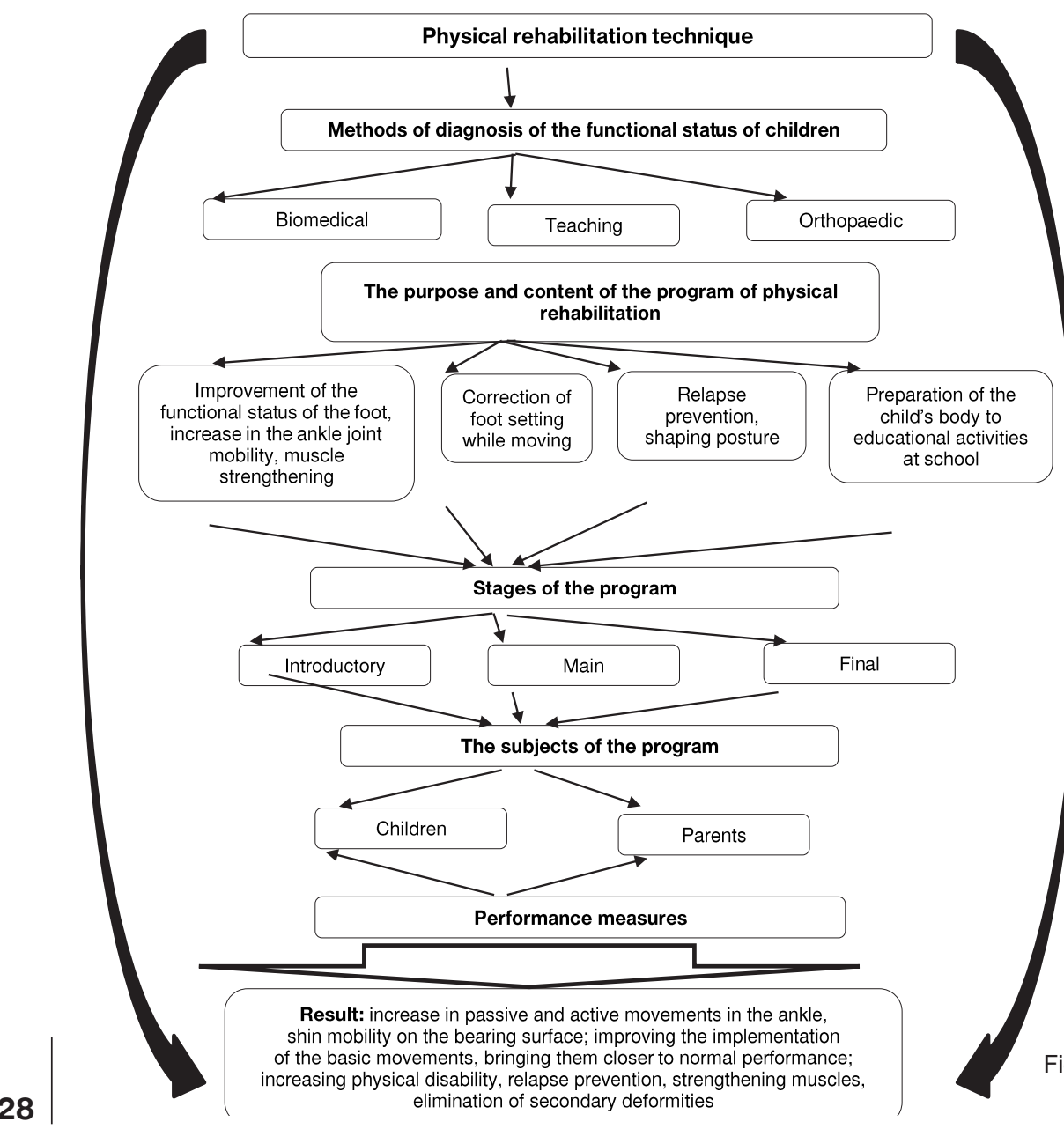

Figure 1. The technique of physical rehabilitation of children with congenital clubfoot 
A principal feature of physical rehabilitation of children is the active involvement of parents in the process, establishing close and trusting relationships with them before the beginning of classes, providing them with the necessary knowledge about the impact of physical rehabilitation and its proper application, as well as with the system of skills required for the organization of physical rehabilitation at home, which will lead to the assumed end result.

The structure of the organization of physical rehabilitation should include the following basic components: the system of training by a specialist in physical rehabilitation for work with children with congenital clubfoot, the substantiation of the system of work with the child, which logically and consistently includes all necessary actions, a program of physical rehabilitation with a detailed distribution of components and differentiation depending on the children's capabilities, the system of working with parents, including training and acquisition of theoretical knowledge and practical skills.

Considering the specificity of violations and psychological peculiarities of the given age during physical therapy, it is necessary to follow the instructions of training exercises in order to master the technique of performing exercises and the distribution of the load according to age and the individual capabilities of children. Positive effects of physical rehabilitation, correction of major and related disorders in development demand a combination of all means of rehabilitation, namely: therapeutic massage, physiotherapy procedures, orthopaedic intervention, and orthopaedic footwear.

In the course of physical rehabilitation, considerable attention was paid to the psychological peculiarities of children of this age. Collaboration with parents implied the attitude towards them as full-fledged partners.

\section{Ethical approval}

The research related to human use has been complied with all the relevant national regulations and institutional policies, has followed the tenets of the Declaration of Helsinki, and has been approved by the authors' institutional review board or an equivalent committee.

\section{Informed consent}

Informed consent has been obtained from the legal guardians of all individuals included in this study.

\section{Results}

At the beginning of the study, a significant difference was found between the length and the width of the feet in children with congenital clubfoot and in their peers without developmental disorders. The foot length was significantly lower in children with congenital clubfoot than in those without developmental abnormalities: $145 \pm 0.62$ and $174 \pm$ $1.16 \mathrm{~mm}(p<0.05)$ (left leg), $145 \pm 0.66$ and $174 \pm 1.16 \mathrm{~mm}$ $(p<0.05)$ (right leg) in 4-year-olds; $153 \pm 1.22$ and $186 \pm$ $1.70 \mathrm{~mm}(p<0.05)$ (left leg), $153 \pm 1.41$ and $186 \pm 1.67 \mathrm{~mm}$ $(p<0.05)$ (right leg) in 5-year-olds, respectively. The smaller foot length in children with congenital clubfoot is a characteristic feature. In foot width analysis, greater values were observed for congenital clubfoot than in the subjects without developmental disorders: $71.6 \pm 0.34$ and $61 \pm$ $0.55 \mathrm{~mm}$ (left leg), $71.7 \pm 0.32$ and $61 \pm 0.54 \mathrm{~mm}$ (right leg) in 4-year-olds; $74.5 \pm 0.44$ and $64.2 \pm 0.57 \mathrm{~mm}$ (left leg), $74.6 \pm 0.48$ and $64.4 \pm 0.54 \mathrm{~mm}$ (right leg) in 5-year-olds, respectively. The survey confirms the data on the reduction of the foot length and the increase of the foot width in children with congenital clubfoot [5, 7, 25].

An analysis of contemporary research has found that in the case of congenital clubfoot, the active foot flexion is considerably worse $[3,8,12]$. Normally, it ranges from 70 $75^{\circ}$ to $80-85^{\circ}$ relative to the position of the foot to shin.

The study of the back of the foot (dorsiflexion) while sitting was conducted actively and passively. In peers without violations (control group 2), active back flexion was within the normal range: $74-87^{\circ}$ at the beginning of the study, $74-86^{\circ}$ at the end of the study (Table 3 ).

At baseline, active and passive back flexion of the foot in children with congenital clubfoot from the main group was significantly smaller than the required parameters for the proper functioning of the child's foot: active back flexion of the left leg: $106.35 \pm 0.48^{\circ}$; passive back flexion of the left leg: $89.71 \pm 0.13^{\circ}$; active back flexion of the right leg: $106.53 \pm$ $0.68^{\circ}$; passive back flexion of the right leg: $89.62 \pm 0.20^{\circ}$.

Table 3. Indicators of active and passive rear flexion in the ankle joint $\left({ }^{\circ}, M \pm m\right)$

\begin{tabular}{|c|c|c|c|c|c|}
\hline \multirow{2}{*}{ Study stages } & \multirow{2}{*}{ Groups } & \multicolumn{2}{|c|}{ Left leg } & \multicolumn{2}{|c|}{ Right leg } \\
\hline & & actively & passively & actively & passively \\
\hline \multirow{3}{*}{ At the beginning } & $\begin{array}{l}\text { Main group } \\
\quad(n=34)\end{array}$ & $106.35 \pm 0.48^{\star \star *}$ & $89.71 \pm 0.13^{\star \star *}$ & $106.53 \pm 0.68^{* \star *}$ & $89.62 \pm 0.20^{\star \star *}$ \\
\hline & $\begin{array}{l}\text { Control group } 1 \\
\quad(n=34)\end{array}$ & $106.24 \pm 0.49^{\star \star \star *}$ & $89.06 \pm 0.25^{\star \star \star \star}$ & $106.38 \pm 0.65^{\star \star \star \star}$ & $89.24 \pm 0.24^{\star \star \star *}$ \\
\hline & $\begin{array}{c}\text { Control group } 2 \\
\quad(n=34)\end{array}$ & $79.94 \pm 0.60$ & $76.56 \pm 0.53$ & $80.06 \pm 0.57$ & $76.68 \pm 0.49$ \\
\hline \multirow{3}{*}{ At the end } & $\begin{array}{l}\text { Main group } \\
\quad(n=34)\end{array}$ & $87.29 \pm 0.46^{*}, * *{ }^{* * *}$ & $78.56 \pm 0.20^{*},{ }^{* *}$ & $87.85 \pm 0.70^{*}, * \star{ }^{* \star * *}$ & $78.56 \pm 0.50^{*},{ }^{* *}$ \\
\hline & $\begin{array}{l}\text { Control group } 1 \\
\quad(n=34)\end{array}$ & $106.15 \pm 0.51^{* * \star *}$ & $89.03 \pm 0.26^{\star \star \star \star}$ & $106.29 \pm 0.65^{\star \star \star \star}$ & $89.29 \pm 0.23^{\star \star \star *}$ \\
\hline & $\begin{array}{c}\text { Control group } 2 \\
\quad(n=34)\end{array}$ & $79.88 \pm 0.58$ & $76.50 \pm 0.52$ & $79.97 \pm 0.55$ & $76.74 \pm 0.50$ \\
\hline
\end{tabular}

* probability of differences at $p<0.05$ between indicators at the beginning and the end of the study within the group

** probability of differences at $p<0.05$ between the main group and control group 1

*** probability of differences at $p<0.05$ between the main group and control group 2

**** probability of differences at $p<0.05$ between control group 1 and control group 2 
The active and passive back flexion in children with congenital clubfoot from the main group significantly improved during the study and approached the level of their peers without disabilities: active back flexion of the left leg: $87.29 \pm$ $0.46^{\circ}(p<0.05)$; passive back flexion of the left leg: $78.56 \pm$ $0.20^{\circ}(p<0.05)$; active back flexion of the right leg: $87.85 \pm$ $0.70^{\circ}(p<0.05)$; passive back flexion of the right leg: $78.56 \pm$ $0.50^{\circ}(p<0.05)$.

The active and passive back flexion of the foot in children with congenital clubfoot from control group 1 changed significantly as compared with baseline: active back flexion of the left leg: $106.15 \pm 0.51^{\circ}$; passive back flexion of the left leg: $89.03 \pm 0.26^{\circ}$; active back flexion of the right leg: $106.29 \pm$ $0.65^{\circ}$; passive back flexion of the right leg: $89.29 \pm 0.23^{\circ}$.

The formative experiment confirmed the effectiveness of the physical rehabilitation technique to improve the foot function during bending to the back: passive bending in the left leg increased by $11.15^{\circ}$, in the right leg by $11.06^{\circ}$, active bending by $19.06^{\circ}$ and $18.68^{\circ}$, respectively $(p<0.05)$ in the main group; control group 1 (who worked with traditional methods) remained at the same levels (increase: $0.03-0.09^{\circ} ; p>0.05$ ) at the rate of $60-75^{\circ}$ (control group 2 involved children without developmental disorders). Meanwhile, the main group recorded a $14.24^{\circ}$ growth of mobility in the left and $8.82^{\circ}$ in the right tibia $(p<0.05)$, and in the control group 1 the registered rates remained the same (increase: $\left.0.15-0.22^{\circ} ; p>0.05\right)$.

The total mobility in the tibia bearing surface is presented in Table 4.

The survey showed that the mobility of the tibia on the bearing surface in children with congenital clubfoot was worse than that in their peers without disabilities. At baseline, the mobility in the ankle joint in the main group and in control group 1 was not much different. The subjects in control group 1 and control group 2 presented no significant change in the mobility of the ankle joint.

It should be stated that in the main group of children undergoing physical rehabilitation, there have been significant improvements in mobility: $9-15^{\circ}$ on average; $44.85 \pm 0.55^{\circ}$ and $45.09 \pm 0.64^{\circ}$ at baseline, $59.09 \pm 0.47^{\circ}$ and $53.91 \pm 0.69^{\circ}$ at the end of the study $(p<0.05)$. The results of the total mobility in children of the main group conclusively confirm the effectiveness of the corrective measures.

Table 4. The results for the total mobility of the tibia bearing surface $\left({ }^{\circ}, M \pm m\right)$

\begin{tabular}{|c|c|c|c|c|}
\hline \multicolumn{2}{|l|}{ Study stages } & $\begin{array}{l}\text { Main group } \\
\quad(n=34)\end{array}$ & $\begin{array}{c}\text { Control group } 1 \\
\quad(n=34)\end{array}$ & $\begin{array}{c}\text { Control group } 2 \\
\quad(n=34)\end{array}$ \\
\hline \multirow{2}{*}{ At the beginning } & left leg & $44.85 \pm 0.55^{\star \star \star}$ & $46.03 \pm 0.61^{\text {****}}$ & $69.85 \pm 0.72$ \\
\hline & right leg & $45.09 \pm 0.64^{\star \star *}$ & $46.82 \pm 0.56^{\star \star \star \star}$ & $70.59 \pm 0.80$ \\
\hline \multirow{2}{*}{ At the end } & left leg & $59.09 \pm 0.47^{*}, * *, * * * *$ & $46.24 \pm 0.62^{* * *}$ & $69.91 \pm 0.71$ * \\
\hline & right leg & $53.91 \pm 0.69^{*}, * *, * * * *$ & $46.97 \pm 0.54^{\star \star *}$ & $70.68 \pm 0.79^{\star}$ \\
\hline
\end{tabular}

* probability of differences at $p<0.05$ between indicators at the beginning and the end of the study within the group

** probability of differences at $p<0.05$ between the main group and control group 1

${ }^{* * *}$ probability of differences at $p<0.05$ between the main group and control group 2

${ }^{* * \star *}$ probability of differences at $p<0.05$ between control group 1 and control group 2

Table 5. Results of the walking exercises in the study groups (points, $M \pm m$ )

\begin{tabular}{|c|c|c|c|c|c|c|}
\hline \multirow{2}{*}{$\begin{array}{l}\text { Walking } \\
\text { exercises }\end{array}$} & \multicolumn{2}{|c|}{$\begin{array}{l}\text { Main group } \\
(n=34)\end{array}$} & \multicolumn{2}{|c|}{$\begin{array}{l}\text { Control group } 1 \\
\quad(n=34)\end{array}$} & \multicolumn{2}{|c|}{$\begin{array}{l}\text { Control group } 2 \\
\quad(n=34)\end{array}$} \\
\hline & at the beginning & at the end & at the beginning & at the end & at the beginning & at the end \\
\hline 1 & $1.18 \pm 0.09^{* * *}$ & $3.00 \pm 0.00^{*},{ }^{* *}$ & $1.21 \pm 0.09^{\star \star \star \star}$ & $1.32 \pm 0.11$ & $2.74 \pm 0.08$ & 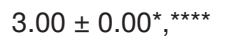 \\
\hline 2 & $0.82 \pm 0.08^{\star * *}$ & $3.00 \pm 0.00^{*},{ }^{* *}$ & $0.85 \pm 0.07^{\star \star \star *}$ & $0.88 \pm 0.06$ & $3.00 \pm 0.00$ & $3.00 \pm 0.00^{\star * * *}$ \\
\hline 3 & $0.79 \pm 0.08^{* * *}$ & $2.56 \pm 0.09^{*},{ }^{* *}$ & $0.76 \pm 0.07^{\star * \star *}$ & $0.82 \pm 0.07$ & $3.00 \pm 0.00$ & $3.00 \pm 0.00^{* \star * * * * * *}$ \\
\hline 4 & $0.74 \pm 0.08^{* * *}$ & $3.00 \pm 0.00^{*}, * *$ & $0.74 \pm 0.08^{* \star \star *}$ & $0.82 \pm 0.07$ & $3.00 \pm 0.00$ & $3.00 \pm 0.00^{\star * * *}$ \\
\hline 5 & $2.47 \pm 0.09^{\star \star \star}$ & $3.00 \pm 0.00^{*}$, ** & $2.38 \pm 0.08^{* \star \star *}$ & $2.44 \pm 0.09$ & $3.00 \pm 0.00$ & $3.00 \pm 0.00^{\star \star \star *}$ \\
\hline 6 & $1.12 \pm 0.08^{\star \star \star}$ & $3.00 \pm 0.00^{*},{ }^{* *}$ & $1.12 \pm 0.08^{\star \star \star *}$ & $1.35 \pm 0.11^{*}$ & $3.00 \pm 0.00$ & $3.00 \pm 0.00^{\star \star \star *}$ \\
\hline 7 & $0.68 \pm 0.08^{\star \star *}$ & $2.79 \pm 0.07^{*}$, ,* & $0.74 \pm 0.08^{* * * *}$ & $0.79 \pm 0.07$ & $2.76 \pm 0.07$ & $2.79 \pm 0.07^{\star * \star *}$ \\
\hline 8 & $0.91 \pm 0.05^{\star \star \star}$ & $3.00 \pm 0.00^{*},{ }^{* *}$ & $0.91 \pm 0.05^{\star \star \star \star}$ & $0.91 \pm 0.05$ & $2.88 \pm 0.06$ & 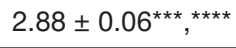 \\
\hline 9 & $2.21 \pm 0.07^{\star \star *}$ & $3.00 \pm 0.00^{*},{ }^{* *}$ & $2.18 \pm 0.07^{\star \star \star \star}$ & $2.24 \pm 0.07$ & $3.00 \pm 0.00$ & $3.00 \pm 0.00^{\star * \star *}$ \\
\hline 10 & $0.91 \pm 0.13^{* \star *}$ & $3.00 \pm 0.00^{*},{ }^{* *}$ & $0.94 \pm 0.13^{* \star \star \star}$ & $1.06 \pm 0.12$ & $2.74 \pm 0.08$ & $2.79 \pm 0.07^{\star \star \star \star}$ \\
\hline 11 & $0.91 \pm 0.13^{* * *}$ & $3.00 \pm 0.00^{*}, * *$ & $0.94 \pm 0.13^{* * * *}$ & $1.09 \pm 0.11$ & $2.71 \pm 0.08$ & $2.76 \pm 0.07^{\star \star \star *}$, \\
\hline
\end{tabular}

See the 'Organization of the research' section for the explanation of walking exercises 1-11.

* probability of differences at $p<0.05$ between indicators at the beginning and the end of the study within the group

** probability of differences at $p<0.05$ between the main group and control group 1

*** probability of differences at $p<0.05$ between the main group and control group 2 
Table 6. Results of the Bondarevsky test in the study groups with eyes open (s, $M \pm m$ )

\begin{tabular}{|l|c|c|c|}
\hline \multirow{2}{*}{ Groups } & Study stages & Left leg & Right leg \\
\hline \multirow{2}{*}{ Main group } & at the beginning & $7.59 \pm 0.59$ & $8.44 \pm 0.54$ \\
\cline { 2 - 4 } & at the end & $28.76 \pm 1.32^{*, * *}$ & $28.50 \pm 1.30^{*, * *}$ \\
\hline \multirow{2}{*}{ Control group 1 } & at the beginning & $8.56 \pm 0.57$ & $8.21 \pm 0.59$ \\
\cline { 2 - 4 } & at the end & $9.18 \pm 0.52$ & $9.09 \pm 0.54$ \\
\hline \multirow{2}{*}{ Control group 2 } & at the beginning & $26.09 \pm 1.02^{* * *, * * *}$ & $26.97 \pm 1.02^{* * *,, * * *}$ \\
\cline { 2 - 4 } & at the end & $28.50 \pm 1.09^{*},{ }^{* * * *}$ & $29.00 \pm 0.98^{*, * * * *}$ \\
\hline
\end{tabular}

* probability of differences at $p<0.05$ between indicators at the beginning and the end of the study within the group

** probability of differences at $p<0.05$ between the main group and control group 1

*** probability of differences at $p<0.05$ between the main group and control group 2

**** probability of differences at $p<0.05$ between control group 1 and control group 2

Table 7. Results of the Bondarevsky test in the study groups with eyes closed (s, $M \pm m$ )

\begin{tabular}{|l|c|c|c|}
\hline Groups & Study stages & Left leg & Right leg \\
\hline \multirow{2}{*}{ Main group } & at the beginning & $0.82 \pm 0.12$ & $0.76 \pm 0.11$ \\
\cline { 2 - 4 } & at the end & $3.32 \pm 0.29^{* * * *, * * *}$ & $3.41 \pm 0.24^{*, * *, * * *}$ \\
\hline \multirow{2}{*}{ Control group 1 } & at the beginning & $0.97 \pm 0.13$ & $0.74 \pm 0.11$ \\
\cline { 2 - 4 } & at the end & $1.03 \pm 0.13$ & $0.88 \pm 0.11$ \\
\hline \multirow{2}{*}{ Control group 2 } & at the beginning & $2.68 \pm 0.23^{* * *, * * * *}$ & $2.44 \pm 0.24^{* * *, * * * *}$ \\
\cline { 2 - 4 } & at the end & $2.85 \pm 0.24^{* * * *}$ & $2.77 \pm 0.21^{* * * *}$ \\
\hline
\end{tabular}

* probability of differences at $p<0.05$ between indicators at the beginning and the end of the study within the group

** probability of differences at $p<0.05$ between the main group and control group 1

*** probability of differences at $p<0.05$ between the main group and control group 2

**** probability of differences at $p<0.05$ between control group 1 and control group 2

Table 8. Results of the running exercises in the study groups (points, $M \pm m$ )

\begin{tabular}{|c|c|c|c|c|}
\hline Exercise & Study stages & $\begin{array}{l}\text { Main group } \\
\quad(n=34)\end{array}$ & $\begin{array}{l}\text { Control group } 1 \\
\quad(n=34)\end{array}$ & $\begin{array}{l}\text { Control group } 2 \\
\quad(n=34)\end{array}$ \\
\hline \multirow{2}{*}{1} & at the beginning & $0.82 \pm 0.08^{\bullet}$ & $0.82 \pm 0.07^{\bullet \bullet}$ & $3.00 \pm 0.00^{\bullet}, \cdot \bullet$ \\
\hline & at the end & $3.00 \pm 0.00^{*},{ }^{* *}$ & $0.88 \pm 0.06^{\star \star \star \star}$ & $3.00 \pm 0.00$ \\
\hline \multirow{2}{*}{2} & at the beginning & $0.85 \pm 0.08^{\bullet}$ & $0.94 \pm 0.11^{\bullet \bullet}$ & $2.56 \pm 0.00^{\bullet}, \bullet$ \\
\hline & at the end & $3.00 \pm 0.00^{*}, * *, * * *$ & $1.03 \pm 0.12^{* * * *}$ & $2.85 \pm 0.06^{*}$ \\
\hline \multirow{2}{*}{3} & at the beginning & $1.06 \pm 0.08^{\bullet}$ & $1.03 \pm 0.07^{\bullet \bullet}$ & $2.71 \pm 0.08 \cdot, \cdot \bullet$ \\
\hline & at the end & $3.00 \pm 0.00^{*}$, ** & $1.15 \pm 0.08^{\star * \star *}$ & $3.00 \pm 0.00^{*}$ \\
\hline \multirow{2}{*}{4} & at the beginning & $1.59 \pm 0.08^{\bullet}$ & $1.62 \pm 0.08^{\bullet \bullet}$ & $2.71 \pm 0.08^{\bullet}, \bullet$ \\
\hline & at the end & $3.00 \pm 0.00^{*}, * *, * * *$ & $1.79 \pm 0.07^{\star \star *}$ & $2.76 \pm 0.07$ \\
\hline \multirow{2}{*}{5} & at the beginning & $0.29 \pm 0.08^{\bullet}$ & $0.41 \pm 0.08^{\bullet \bullet}$ & $2.71 \pm 0.08^{\bullet}, \bullet$ \\
\hline & at the end & $2.88 \pm 0.06^{*},{ }^{* *}$ & $0.65 \pm 0.08^{\star \star \star \star}$ & $2.76 \pm 0.07$ \\
\hline \multirow{2}{*}{6} & at the beginning & $2.00 \pm 0.00^{\bullet}$ & $2.03 \pm 0.03^{\bullet \bullet}$ & $2.12 \pm 0.06^{\bullet}, \bullet$ \\
\hline & at the end & $2.91 \pm 0.05^{\star},{ }^{* *}$ & $2.09 \pm 0.05^{\star \star \star *}$ & $2.18 \pm 0.07$ \\
\hline
\end{tabular}

See the 'Organization of the research' section for the explanation of running exercises 1-6.

- probability of differences at $p<0.05$ between the main group and control group 2 at the beginning

-• probability of differences at $p<0.05$ between control group 1 and control group 2 at the beginning

* probability of differences at $p<0.05$ between indicators at the beginning and the end of the study within the group

** probability of differences at $p<0.05$ between the main group and control group 1 at the end

*** probability of differences at $p<0.05$ between the main group and control group 2 at the end

**** probability of differences at $p<0.05$ between control group 1 and control group 2 at the end 
Table 9. Results of determining physical working capacity in the study groups $(M \pm m)$

\begin{tabular}{|c|c|c|c|c|}
\hline \multicolumn{2}{|l|}{ Ruffier index } & $\begin{array}{l}\text { Main group } \\
\quad(n=34)\end{array}$ & $\begin{array}{l}\text { Control group } 1 \\
\qquad(n=34)\end{array}$ & $\begin{array}{c}\text { Control group } 2 \\
(n=34)\end{array}$ \\
\hline \multirow{2}{*}{ At the beginning } & index & $8.69 \pm 0.40$ & $8.37 \pm 0.38$ & $8.20 \pm 0.37$ \\
\hline & level & average & average & average \\
\hline \multirow{2}{*}{ At the end } & index & $5.76 \pm 0.28^{*},{ }^{* *},{ }^{* * *}$ & $7.79 \pm 0.34$ & $7.58 \pm 0.36$ \\
\hline & level & good & average & mean \\
\hline
\end{tabular}

* probability of differences at $p<0.05$ between indicators at the beginning and the end of the study within the group

** probability of differences at $p<0.05$ between the main group and control group 1

*** probability of differences at $p<0.05$ between the main group and control group 2

Average scores for walking exercises in children in all 3 groups are shown in Table 5.

Analysing the data shown in Table 5, one can see that the indices of all control exercises in the children of the main group were significantly better at the end of the study $(p<0.05)$, whereas in control group 1 , the improvement involved walking in broad steps only $(p<0.05)$, and in control group 2, walking with a high knee lift $(p<0.05)$. At the end of the study, the performance of children in the main group was higher than in control group 2 (peers without developmental disorders) with regard to 4 exercises.

Exercising equilibrium contributes to the development of movements coordination, dexterity, courage, perseverance, determination, self-confidence, and the right posture in pre-schoolers. At first, the children maintained balance with their eyes open (Table 6).

At the beginning of the study, the results of the Bondarevsky test confirmed the deterioration of balance in children with congenital clubfoot as compared with their peers without developmental disorders $(p<0.05)$. The comparison of the indicators at the beginning and at the end of the study showed a significant improvement in the performance of the Bondarevsky test in the main group $(p<0.05)$. At the same time, by the end of the study, the subjects of control group 1 did not change significantly.

The improvement in balance contributed to the implementation of special physical exercises in static and dynamic positions. Static exercises included keeping balance in a particular position (squatting on toes, standing on one leg, etc.), and dynamic ones - in motion (walking on a board, gymnastic bench, or log, changing direction during running, sudden stops in moving games, etc.).

The children experienced significant difficulties during the Bondarevsky test with their eyes closed (Table 7). When analysing the obtained data, one can observe that at the beginning of the study, only children without developmental disorders were able to keep the commanded pose for 3-6 seconds. The children with congenital clubfoot could keep this position for not longer than 2 seconds, which proves the negative influence of congenital clubfoot on the development of balance in children.

The comparison of the mean values of the Bondarevsky test at the beginning and at the end of the study shows minor changes in the children of control group 1 and control group 2. In turn, a significant increase in the indicators was found in the main group $(p<0.05)$ :

- the main group (left/right leg): $0.82 \pm 0.12 / 0.76 \pm 0.11 \mathrm{~s}$ at the beginning of the study, $3.32 \pm 0.29 / 3.41 \pm 0.24 \mathrm{~s}$ at the end of the study (the figures increased 4 times) $(p<0.05)$;

- control group 1 (left/right leg): $0.97 \pm 0.13 / 0.74 \pm 0.11 \mathrm{~s}$ the end of the study (there were slight changes in the indicators);

- control group 2 (left/right leg): $2.68 \pm 0.23$ / $2.44 \pm 0.24 \mathrm{~s}$ at the beginning of the study, $2.85 \pm 0.24 / 2.77 \pm 0.21 \mathrm{~s}$ at the end of the study (there were slight changes in the indicators).

Hence, there is a need for timely and long-term physical rehabilitation for congenital clubfoot.

Average scores for running exercises in the children of the 3 groups are shown in Table 8 .

When analysing the performance of running exercises among children with congenital clubfoot at the beginning of the study, we discovered that the subjects presented disturbed coordination of hands and feet movements. There was no correct placement of the foot to the ground during slow or rapid running, varus position of the foot, weak foot repulsion from the ground, low running speed.

The observation and testing revealed that in the children with congenital clubfoot, one of the problems with running exercises was that the foot was not put elastically rolled from the heel to the toe.

When analysing the running exercises results at the end of the study, one can notice that in the children of control group 1, there was no significant improvement:

- running on socks: $0.82 \pm 0.07$ points at the beginning of the study, $0.88 \pm 0.06$ points at the end of the study;

- high knee racing: $0.94 \pm 0.11$ points at the beginning of the study, $1.03 \pm 0.12$ points at the end of the study;

- running a wide step: $1.03 \pm 0.07$ points at the beginning of the study, $1.15 \pm 0.08$ points at the end of the study;

- running with overcoming obstacles - running around objects: $1.62 \pm 0.08$ points at the beginning of the study, $1.79 \pm 0.07$ points at the end of the study;

- running with overcoming obstacles - jump items: $0.41 \pm$ 0.08 points at the beginning of the study, $0.65 \pm 0.08$ points at the end of the study;

- running the distance of 100-150 $\mathrm{m}$ at an average speed 3-4 times, at a slow pace: $2.03 \pm 0.03$ points at the beginning of the study, $2.09 \pm 0.05$ points at the end of the study.

The participants without developmental disorders performed in all exercises at the end of the study almost as well as at the beginning of the study.

Owing to the applied physical rehabilitation, the children of the main group completely independently, without mistakes performed the following exercises $(3.00 \pm 0.00$ points):

- running on toes, running with high knee lift;

- running a wide step;

- running with overcoming obstacles - running around objects. 
When running with overcoming obstacles - jump items, and running the distance of 100-150 $\mathrm{m}$ at an average speed 3-4 times, the children of the main group did the exercises on their own, only a few of them with minor mistakes (2.88 \pm 0.06 and $2.91 \pm 0.05$ points).

During the course of physical rehabilitation, attention was paid to the development of physical efficiency in the children of the main group. At the beginning of the study, the average index of physical capacity was $8.69 \pm 0.40$ in the main group, $8.37 \pm 0.38$ in control group 1 , and $8.20 \pm 0.37$ in control group 2; in all groups, it corresponded to the average level of physical capacity (Table 9 ).

At the end of the study, the average indicators of physical capacity in control group $1(7.79 \pm 0.34)$ and in control group $2(7.58 \pm 0.36)$ did not change significantly and corresponded to the average level of physical capacity.

The average indicators of physical capacity in the main group at the end of the study equalled $5.76 \pm 0.28(p<0.05)$, which already corresponds to a good level of physical capacity and proves the effectiveness of the applied physical rehabilitation in enhancing physical fitness in children.

Insignificant improvements in physical fitness in the children of control group 1 and control group 2 could take place at the expense of the children's growth and the reduction of heart rate in a state of rest.

The effectiveness of the developed technique of physical rehabilitation makes it possible to state the growth of physical capacity (to a high level in $14.7 \%$ and to a good level in $52.9 \%$ of the children in the main group, with the absence of the high level and the presence of the good level in $26.5 \%$, respectively, at the beginning of the experiment). In the control groups, the indicators analysed during the school year remained at the achieved level.

\section{Discussion}

In the course of the study, the fundamental provisions on the significance and effectiveness of the integrated approach in the process of physical rehabilitation among children with congenital clubfoot have been confirmed [23, 24, 26-28]. Among the reasons for congenital clubfoot relapses, one should consider insufficient correction of the pathology (false relapse), as well as the lack of appropriate and prolonged use of physical rehabilitation equipment, with the necessary orthopaedic support. There are extended data on the development of motor skills in children with congenital clubfoot and the inconsistency in the development of leg muscles in comparison with peers without developmental disorders [25, 29, 30], supplemented with scientific research on the purpose and content of the physical rehabilitation program and baseline parameters of preschool children [31, 32].

The effectiveness of the developed concept of physical rehabilitation for congenital clubfoot was characterized by the systematic approach to the process of working with the child, adherence to the generally accepted conditions for conducting occupations of motor activity in preschool settings, the priority of the role of a specialist in physical rehabilitation in this process, implementation in accordance with systems for working with children [33-35].

The analysis of the results of implementing the technique of physical rehabilitation among children with congenital clubfoot gives grounds to state its effectiveness in correcting the pathological position of the foot and the main movements, developing the mobility of the ankle joint, physical qualities, and physical performance, as well as improving the children's functional status [35-37].

\section{Conclusions}

The technique of physical rehabilitation of preschool children with congenital clubfoot, taking into account the disadvantages of the existing organization and the content of the process, determines the directions of the process improvement on the basis of the implementation of the requirements of the general, as well as didactic (availability and individualization, regularity) and methodical (compensatory, correctional and developmental orientation, progression of influence, continuity, age adequacy) principles of physical education. During the formation of the content of classes, the technique considers individual morphology and function of the foot and the entire musculoskeletal system, among other systems especially muscular and cardiovascular.

The comprehensive approach that provides for a system of training specialists (mastering methods of rehabilitation and complex examination, defining the content of recommendations to be implemented by the parents, forming an individually oriented content of lessons) is recognized as optimal for the effect of physical rehabilitation of pre-schoolers with congenital clubfoot. The cooperation with parents includes open lessons, conversations, trainings, individual and group consultations. The influence of physical rehabilitation on a child's body results in normalization of foot morphology and function, elimination of relapses, training of main movements, and improvement of physical development, functional indicators, and physical qualities to the level of peers without violations of development. The main means of influence are selected physical exercises during exercise therapy, physiotherapy (common procedures, everyday, not more than 3 times 10-30 minutes during the main and final stages of the program implementation), the use of orthopaedic means and footwear.

\section{Financing}

The research was carried out in accordance with the scientific program of the Department of Health and Physical Therapy of the National University of Water and Environmental Engineering, Rivne, Ukraine for 2017-2021 entitled 'Rehabilitation and recreation technologies for recovery and support of human health' (state registration number: 0117U007676).

\section{Disclosure statement}

No author has any financial interest or received any financial benefit from this research.

\section{Conflict of interest}

The authors state no conflict of interest.

\section{References}

1. Chotigavanichaya C, Scaduto AA, Snelson D, Otsuka NY. A novel orthosis for the treatment of clubfoot. J Pediatr Orthop B. 2003;12(4):272-276; doi: 10.1097/01.bpb. 0000078724.48512.b0.

2. Sud A, Tiwari A, Sharma D, Kapoor S. Ponseti's vs. Kite's method in the treatment of clubfoot - a prospective randomised study. Int Orthop. 2008;32(3):409-413; doi: 10.1007/s00264-007-0332-y.

3. Mykhaylova N, Grygus I. Physical rehabilitation of children with congenital clubfoot [in Polish]. Potrzeby i standardy współczesnej rehabilitacji. V Międzynarodowe Dni Rehabilitacji. Rzeszów; 2013; 108-109.

4. Papavasiliou VA, Papavasiliou AV. A novel surgical option for the operative treatment of clubfoot. Acta Orthop Belg. 2004;70(2):155-161. 
5. Barhatov MV, Galaktionova MJ, Karpushkina OV. Integrated approach in the treatment of congenital clubfoot [in Russian]. Sovremennye Naukoemkie Tehnologii. 2006; 5:64.

6. Faulks S, Luther B. Changing paradigm for the treatment of clubfeet. Orthop Nurs. 2005;24(1):25-30; doi: 10.1097/ 00006416-200501000-00009.

7. Mykhaylova N, Grygus I. Improving physical performance in children with congenital clubfoot. J Orthop Trauma Surg Rel Res. 2013;3(33):53-58.

8. Mykhaylova N, Prusik K, Prusik K, Grygus I. Enhancement of functional state of children with congenital clubfoot via physical rehabilitation. Theory Pract Phys Culture. 2014;3:30-32.

9. Cummings RJ, Davidson RS, Armstrong PF, Lehman WB. Congenital clubfoot. Instr Course Lect. 2002;51:385400; doi: 10.2106/00004623-200202000-00018.

10. Behnke RS. Kinetic anatomy, $2^{\text {nd }}$ ed. Champaign: Human Kinetics; 2006.

11. Shikhaleva NG. Treatment of congenital clubfoot in children from one year to seven years with the bone osteosynthesis method [in Russian]. Dis Kand Med Nauk. 14.00.22. 2005;125.

12. Kadzhaya LK. Contemporary approach to treatment of children aged 3-14 with congenital clubfoot [in Russian]. Dis Kand Med Nauk. 14.01.15; 14.03.11. M. 2011;118.

13. Vlasov MV. Surgical treatment of congenital clubfoot in infants [in Russian]. Dis Kand Med Nauk [spec.]. 14.00.22 Travmatologija i ortopedija. 2006;135.

14. Bondarenko RV. Surgical treatment of severe congenital clubfoot in children [in Russian]. Dis Kand Med Nauk 14.00.27. 2006;88.

15. Krestyashin IV. Differential approach to diagnosis and treatment of congenital clubfoot in children [in Russian]. Dis Kand Med Nauk [spec.]. 14.01.19. M. 2011;75.

16. Kosov IS, Kozhevnikov OV, Mihajlova SA, Kralina SJ, Kadzhaya LK. To the pathogenesis of recurrent congenital clubfoot [in Russian]. Vestnik Travmatologii i Ortopedii. 2011;1:45-48.

17. Malyshenko EP. Early conservative treatment of congenital clubfoot with a pneumatic splint [in Russian]. Dis Kand Med Nauk [spec.]. 14.00.35. 2004;85.

18. Dobbs MB, Nunley R, Schoenecker PL. Long-term follow-up of patients with clubfeet treated with extensive soft-tissue release. J Bone Joint Surg Am. 2006;88(5): 986-996; doi: 10.2106/JBJS.E.00114.

19. Skliarenko YT. Traumatology and orthopaedics: a manual [in Ukrainian]. K Zdorovia. 2005;384.

20. Bensahel H, Bienayme B, Jehanno P. History of the functional method for conservative treatment of clubfoot. J Child Orthop. 2007;1(3):175-176; doi: 10.1007/s11832007-0043-3.

21. Barker SL, Lavy CB. Correlation of clinical and ultrasonographic findings after Achilles tenotomy in idiopathic club foot. J Bone Joint Surg Br. 2006;88(3):377-379; doi: 10.1302/0301-620X.88B3.17273.

22. Bukup K. A clinical study of bones, joints and muscles [in Russian]. Moscow: Meditsinskaya literatura; 2007.

23. Kononko OL, Svitych K (eds.). The basic program for the development of preschool age children 'I and the world' [in Ukrainian]. Kiev: Ministry of Education and Science, Ukrainian Academy of Pedagogical Sciences; 2008.

24. Proskura OV, Kochina LP, Kuzmenko VU, Kudikina NV. Child. Program of upbringing and education of children education. Letter of the Ministry of Education and Science of Ukraine dated 08.12.2010, No. 1/11-11177.

25. Golovakha ML, Prusik K. Improving the process of physical rehabilitation in congenital clubfoot [in Russian]. J Health Sci. 2013;3(8):37-46.

26. Kołban M, Kołodziej J, Radomski S, Zacha S. Classification of results of treatment of congenital clubfeet [in Polish]. Chir Narzadow Ruchu Ortop Pol. 2001;66(5): 517-522.

27. Richards BS, Johnston CE, Wilson H. Nonoperative clubfoot treatment using the French physical therapy method. J Pediatr Orthop. 2005;25(1):98-102; doi: 10.1097/01241398-200501000-00022.

28. Mykhaylova N, Prusik K, Prusik K, Grygus I. Modern approaches to organization of physical rehabilitation of children with congenital clubfoot [in Russian]. J Health Sci. 2013;3(9):31-40.

29. Yedynak HA, Prusik K. Physical rehabilitation of children with orthopaedic feet deformities with the consideration of the resistance and movement apparatus modifications [in Ukrainian]. J Health Sci. 2013;3(8):27-36.

30. Lejman T, Kowalczyk B. Results of treatment of congenital clubfoot with modified Goldner's technique [in Polish]. Chir Narzadow Ruchu Ortop Pol. 2002;67(4):351-355.

31. Cardy AH, Barker S, Chesney D, Sharp L, Maffulli N, Miedzybrodzka Z. Pedigree analysis and epidemiological features of idiopathic congenital talipes equinovarus in the United Kingdom: a case-control study. BMC Musculoskelet Disord. 2007;8:62; doi: 10.1186/14712474-8-62.

32. Minnikaeva NV. Game activities in the engine mode for older preschool children as a means of creating physical culture personality [in Russian]. Dis Kand Ped Nauk [spec.]. 13.00.04. Teorija i Metodika Fizicheskogo Vospitanija, Sportivnoj Trenirovki, Ozdorovitelnoj i Adaptivnoj Fizicheskoj Kultury M. 2009;24.

33. Słowińska I. Complex diagnostics of common conditions of the motor organ of the developmental age. Reumatologia. 2017;55(4):198-200; doi: 10.5114/reum.2017. 69780.

34. Simovska V, Jakimoska-Jordanoska R, Simovski A. Physical activity levels and screen-based activities in Macedonian school-aged children and young adolescents: an important public health priority. Health Probl Civiliz. 2017;11(3):173-179; doi: 10.5114/hpc.2017.70002.

35. Wójtowicz D, Roshko J, Ptak A, Dębiec-Bąk A, Skrzek A. The efficiency of rehabilitation for self-service eating in institutionalized children aged 2-6 years with mental and motor retardation. Physiother Quart. 2017;25(2):10-16; doi: 10.5114/pq.2018.73367.

36. Chagas DV, Batista LA. Comparison of health outcomes among children with different levels of motor competence. Hum Mov. 2017;18(2):56-61; doi: 10.1515/humo-20170018.

37. Czajka K, Sławińska T, Kołodziej M, Kochan K. Assessment of physical activity by pedometer in Polish preschool children. Hum Mov. 2015;16(1):15-19; doi: 10.1515/ humo-2015-0021. 